\title{
Quantification of variability in bedform geometry
}

\author{
C. F. van der Mark, ${ }^{1}$ A. Blom, ${ }^{2}$ and S. J. M. H. Hulscher ${ }^{1}$ \\ Received 2 November 2007; revised 3 April 2008; accepted 1 May 2008; published 21 August 2008.
}

[1] We analyze the variability in bedform geometry in laboratory and field studies. Even under controlled steady flow conditions in laboratory flumes, bedforms are irregular in size, shape, and spacing, also in case of well-sorted sediment. Our purpose is to quantify the variability in bedform geometry. We use a bedform tracking tool to determine the geometric variables of the bedforms from measured bed elevation profiles. For each flume and field data set, we analyze variability in (1) bedform height, (2) bedform length, (3) crest elevation, (4) trough elevation, and (5) slope of the bedform lee face. Each of these stochastic variables is best described by a positively skewed probability density function such as the Weibull distribution. We find that, except for the lee face slope, the standard deviation of the geometric variable scales with its mean value as long as the ratio of width to hydraulic radius is sufficiently large. If the ratio of width to hydraulic radius is smaller than about ten, variability in bedform geometry is reduced. An exponential function is then proposed for the coefficients of variation of the five variables to get an estimate of variability in bedform geometry. We show that mean lee face slopes in flumes are significantly steeper than those in the field.

The $95 \%$ and $98 \%$ values of the geometric variables appear to scale with their standard deviation. The above described simple relationships enable us to integrate variability in bedform geometry into engineering studies and models in a convenient way.

Citation: van der Mark, C. F., A. Blom, and S. J. M. H. Hulscher (2008), Quantification of variability in bedform geometry, J. Geophys. Res., 113, F03020, doi:10.1029/2007JF000940.

\section{Introduction}

[2] Bedforms such as river dunes or marine sand waves are rhythmic bed features which develop because of the interaction between water flow and sediment transport. Often bedforms are schematized as a train of regular features (e.g., a sinusoidal wave, a train of identical triangles or smoothly shaped asymmetric forms). The purpose of such a simplification is, for instance, to explain the generation of sand waves through stability analysis [e.g., Hulscher, 1996], or to numerically [e.g., Yoon and Patel, 1996] or experimentally [e.g., Nelson et al., 1993; Lyn, 1993; McLean et al., 1999] analyze the turbulent flow structures over bedforms. Bed elevation profiles from a laboratory flume or the field show that bedforms are not regular (Figure 1), even under steady conditions and for wellsorted sediment [e.g., Nordin, 1971; Paola and Borgman, 1991].

[3] Previous studies have shown that variability in bedform geometry, i.e., size, shape and spacing, is not the exception, but is the character of natural bedforms developing under and interacting with unidirectional flows [Jerolmack and Mohrig, 2005a]. Natural bedform topog-

\footnotetext{
${ }^{1}$ Water Engineering and Management, Civil Engineering, University of Twente, Enschede, Netherlands.

${ }^{2}$ Environmental Fluid Mechanics, Delft University of Technology, Delft, Netherlands.

Copyright 2008 by the American Geophysical Union. 0148-0227/08/2007JF000940\$09.00
}

raphy continuously evolves, i.e., bedforms merge and split [Gabel, 1993], even under steady flow conditions [Leclair, 2002]. Bedform geometry under given flow conditions is modified by variations in the sediment flux [Jerolmack and Mohrig, 2005a]. A modification in bedform geometry induces modification in flow acceleration, which in turn induces modification in the sediment flux [Nelson et al., 1993]. Jerolmack and Mohrig [2005a] hold the nonlinear feedback between topography and sediment transport responsible for the variability in bedform geometry. Jerolmack and Mohrig [2005b] develop a surface evolution model for the topography of bed load dominated sandy rivers. They add a noise term to the sediment flux to account for local fluctuations in the sediment flux. Deterministic model simulations in which the noise term is zero evolve toward a static steady pattern of bedforms, i.e., uniform periodic bedforms. Model simulations in which the noise term has a mean value of zero and is Gaussian distributed evolve toward a bed topography that is continuously varying but in statistical sense homogeneous.

[4] In several studies, we need information not only on the average geometric variables of bedforms, but also on their stochastics. For example, dredging, which is necessary to keep a navigational channel sufficiently deep, requires information on the highest crest elevations. On the other hand, construction of pipelines and cables buried in the sea bed, which may not be exposed to the flow, demands information on the deepest trough elevations. Similarly, safety against uplifting of a tunnel underneath a river bed 


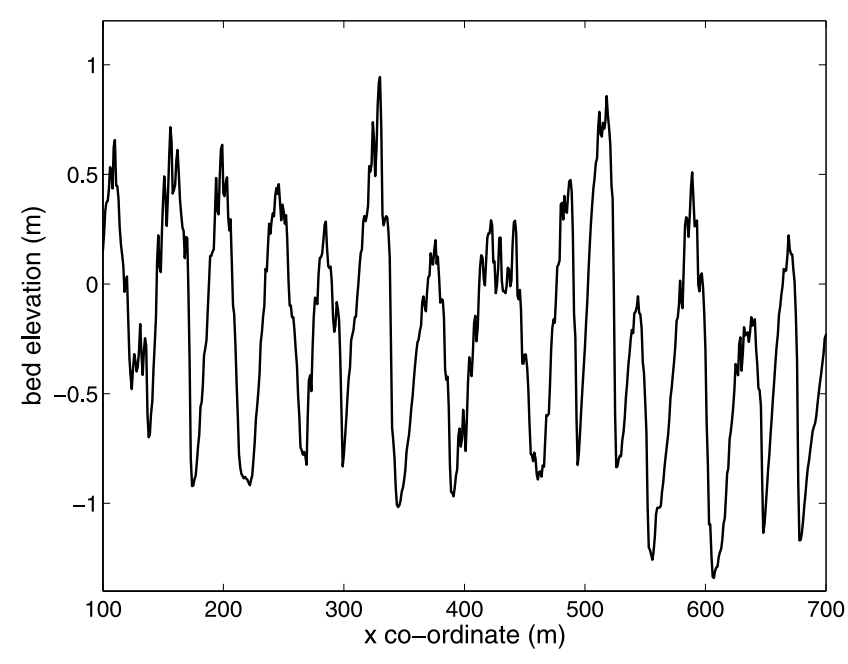

Figure 1. Bed elevation profile of the Waal branch of the Rhine River in Netherlands. Measurements taken on December 11, 2006. Flow is from left to right.

needs to be guaranteed when a deep trough migrates over the tunnel [Amsler and García, 1997].

[5] Furthermore, variability in bedform geometry needs to be taken into account when modeling (1) the thickness of cross-strata sets, (2) vertical sorting, or (3) bed roughness. The first example is illustrated by the fact that the variability in trough elevations is relevant in the reconstruction of the original heights of bedforms from the thickness of crossstrata in preserved deposits as it mainly determines the probability density function of cross-set thickness of preserved bedforms [e.g., Paola and Borgman, 1991; Leclair, 2002]. Second, the variability in trough elevations affects the morphodynamic changes of the river bed when vertical sorting within bedforms plays a role. A model predicting the variability in trough elevations is required as a sub-model for a stochastic model for mass conservation of sediment mixtures [Blom et al., 2008]. The third example concerns the effect of variability in bedform geometry upon form roughness. Form drag due to the presence of bedforms results in a component of flow resistance that is often called form roughness. As form roughness depends on the size, shape, and spacing of the bedforms [e.g., Allen, 1983; Nelson et al., 1993], we hypothesize that the variability in geometric variables of individual bedforms within a reach affects the reach-averaged form roughness. We ground this hypothesis by making an analogy between grain roughness and form roughness. Often the $65 \%, 84 \%$, or $90 \%$ grain size ( $D_{65}, D_{84}$, or $D_{90}$, respectively) is used as a representative diameter of the grains in predicting the grain roughness, as this diameter is representative in its effect on the flow [Van Rijn, 1982]. Analogously, form roughness may also be determined by bedforms that are higher, longer, or steeper than the median or mean bedform height, bedform length, or bedform steepness, respectively.

[6] The aim of this paper is to characterize variability in bedform geometry by analyzing flume and field data. In earlier work, researchers have reported mean values, standard deviations, and histograms of bedform height, bedform length, and bedform steepness (defined as bedform height divided by bedform length) for their own flume or field data set [e.g., Gabel, 1993; Wang and Shen, 1980]. In the present paper we analyze a number of data sets of both flume and field experiments with a wide range of bedform heights and lengths and focus on finding generic relations describing variability in five geometric variables: (1) bedform height, (2) bedform length, (3) crest elevation, (4) trough elevation, and (5) lee face slope. For each of these stochastic variables, we consider (1) its probability density function, (2) its ratio of standard deviation to mean value (coefficient of variation), and (3) its extreme values (95\% and 98\%). In our data analysis, we process each data set in the same way using a new generally applicable bedform tracking tool.

\section{Data}

\subsection{Flume Data}

[7] We use laboratory flume data (Table 1) of Driegen [1986], Klaassen [1990], Leclair [2002], and Blom et al. [2003]. The experiments of Driegen [1986], Klaassen [1990], and Blom et al. [2003] were conducted in the Sand Flume of Delft Hydraulics in Netherlands. Leclair [2002] performed a series of runs under varying flow conditions at Binghamton University (BU), New York, USA. We use the

Table 1. Characteristics of Data

\begin{tabular}{|c|c|c|c|c|c|c|c|c|c|c|}
\hline Data set & $n(-)$ & $m(-)$ & $L(\mathrm{~m})$ & $W(\mathrm{~m})$ & $h(\mathrm{~m})^{\mathrm{a}}$ & $U(\mathrm{~m} / \mathrm{s})^{\mathrm{a}}$ & $D_{10}(\mathrm{~mm})$ & $D_{50}(\mathrm{~mm})$ & $D_{90}(\mathrm{~mm})$ & $\mu_{\Delta}(\mathrm{cm})^{\mathrm{a}}$ \\
\hline Driegen [1986] & 32 & 3 & 50 & 1.5 & $0.087-0.592$ & $0.393-0.861$ & 0.70 & 0.78 & 0.85 & $4.0-17.2$ \\
\hline Driegen [1986] & 3 & 3 & 50 & 1.125 & $0.204-0.306$ & $0.488-0.582$ & 0.70 & 0.78 & 0.85 & $6.5-9.7$ \\
\hline Driegen [1986] & 6 & 3 & 50 & 0.5 & $0.120-0.436$ & $0.417-0.611$ & 0.70 & 0.78 & 0.85 & $3.1-9.8$ \\
\hline Klaassen [1990] & 6 & 3 & 50 & 1.125 & $0.091-0.402$ & $0.488-0.663$ & 0.30 & 0.66 & 2.24 & $2.8-15.2$ \\
\hline Leclair [2002] & 3 & 1 & 7.6 & 0.6 & 0.15 & $0.50-0.75$ & 0.24 & 0.43 & 0.60 & $4.4-5.6$ \\
\hline Blom et al. [2003] & 4 & 3 & 50 & 1.5 & $0.193-0.354$ & $0.59-0.79$ & 0.38 & 1.3 & 9.3 & $1.3-8.5$ \\
\hline Blom et al. [2003] & 4 & 3 & 50 & 1.0 & $0.154-0.389$ & $0.63-0.83$ & $\operatorname{mix}^{b}$ & $\operatorname{mix}^{b}$ & $\operatorname{mix}^{b}$ & $1.1-13.1$ \\
\hline Rhine December 2006 & - & - & 6000 & 250 & 8 & 1.0 & 0.4 & 0.8 & 3 & $25-130$ \\
\hline Rhine March 2007 & - & - & 200 & 60 & 8 & 1.0 & 0.4 & 0.8 & 3 & 30.5 \\
\hline North Loup July 13, 1990 & - & - & 30 & 15 & 0.25 & 0.27 & 0.17 & 0.31 & 1.5 & 7.3 \\
\hline North Loup July 22, 1990 & - & - & 30 & 15 & 0.25 & 0.27 & 0.17 & 0.31 & 1.5 & 9.1 \\
\hline
\end{tabular}

$n$ denotes the number of flume experiments. $m$ denotes the number of transect locations: 1 means that bed elevations were measured in the center line, 3 means that bed elevations were measured in the center line, as well as left and right of the center line. $L$ and $W$ denote the length and width of the flume, or the length and width of the measured field section, respectively. $h, U, D_{x}$, and $\mu_{\Delta}$ denote water depth, average flow velocity, particle diameter for which $x \%$ of the material is finer, and mean bedform height, respectively.

${ }^{a}$ Range within the data set.

${ }^{\mathrm{b}}$ Mixture of three well-sorted size fractions: fine $D_{50}=0.68 \mathrm{~mm}$, medium $D_{50}=2.1 \mathrm{~mm}$ and coarse $D_{50}=5.7 \mathrm{~mm}$. 


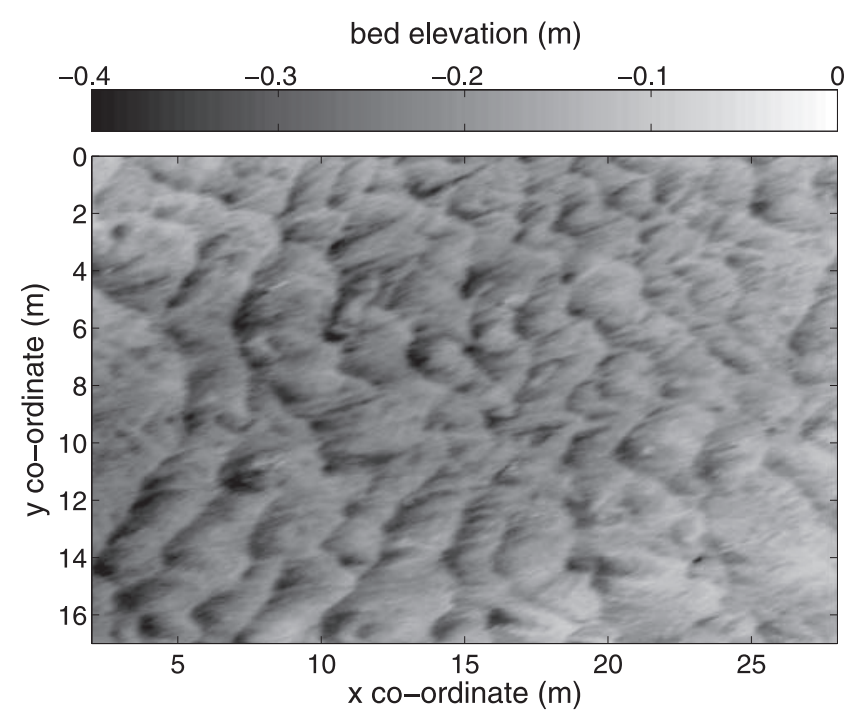

Figure 2. Bed elevation measurements of a part of the North Loup River taken on July 22, 1990 [Mohrig, 1994; Mohrig and Smith, 1996; Jerolmack and Mohrig, 2005b]. Flow is from left to right.

data from the BU runs in which no net aggradation occurs. We consider measured data from the flume region unaffected by the entrance and exit of the flume only. All measurements were taken under equilibrium (i.e., steady and uniform) conditions, which means that bedform geometry, flow, and sediment transport rate varied around steady mean values. We refer to Table 1 for details on the experiments.

\subsection{Field Data}

[8] We consider field data from the Waal branch of the Rhine River in Netherlands, as well as field data from the North Loup River, Nebraska, USA (Table 1). The reaches are not influenced by river bends.

[9] Multi-beam echo sounder measurements were made at two locations within the main channel of the Rhine River branch by the Dutch Ministry of Transport, Public Works and Water Management (Rijkswaterstaat). The first reach, measured on December 11, 2006, is $6 \mathrm{~km}$ long and $250 \mathrm{~m}$ wide, the second reach, measured in March 2007, is $200 \mathrm{~m}$ long and $60 \mathrm{~m}$ wide. Both reaches have a sandy bed: $D_{10} \approx$ $0.4 \mathrm{~mm}, D_{50} \approx 0.8 \mathrm{~mm}, D_{90} \approx 3 \mathrm{~mm}$ [Ten Brinke, 1997]. The measured bed elevations are projected on a regular grid of $1 \times 1 \mathrm{~m}^{2}$ by averaging the available bed elevation measurements (at least 10) within each grid cell. The effect of the averaging procedure on bedform geometry is negligible as the grid size is small with respect to bedform height and length.

[10] The topographic data of the braided North Loup River (Figure 2) are derived from low-altitude aerial photography [Mohrig, 1994; Mohrig and Smith, 1996]. The river bed consists of sand with median grain diameter $D_{50}=$ $0.31 \mathrm{~mm}$ [Mohrig and Smith, 1996]. We consider observations taken on two days (July 13 and 22, 1990), taken with an interval of 2 minutes and 1 minute, respectively, for a period of 2 hours and 40 minutes, respectively. The considered river reach is $30 \mathrm{~m}$ long and $15 \mathrm{~m}$ wide. Approximately constant river stage ensured that flow was essentially steady over the observation period [Jerolmack and Mohrig, 2005b].

\section{Data Processing}

\subsection{Grouping of Streamwise Bed Elevation Profiles}

[11] In the assessment of the variability in bedform geometry we analyze the original bed elevation profiles (BEPs). We only use series of bed elevations measured along a transect, and no time series. In the flume experiments BEPs were measured in streamwise direction. For the field measurements we convert the original bed elevation profiles in $X$ and $Y$ coordinates to bed elevation profiles in the streamwise direction.

[12] Within a data set we can distinguish two types of sets of BEPs (Figure 3): (1) a set of BEPs measured at the same transect (e.g., in the center of a flume) at various moments in time and (2) a set of BEPs measured at the same time, but at different transects (e.g., one BEP measured in the center, one BEP left from the center, and one BEP right from the center of a flume). All BEPs from the flume experiments of Leclair [2002] are of type 1. The BEPs from the Waal branch data measured in December 2006 belong to type 2 . All other flume and field BEPs are of both type 1 and type 2 .

[13] It is allowed to group together bedform geometry derived from BEPs that are statistically homogeneous in both space and time [Paola and Borgman, 1991]. In that case, the statistics of the BEPs as a whole are equal, although individual migrating bedforms continuously merge, split, and thus change in shape and size. We use a spatial scaling technique [Nikora and Hicks, 1997; Jerolmack and Mohrig, 2005b] to verify which BEPs within a data set are statistically homogeneous in space and/or time. The spatial scaling technique treats a series of bed elevations in a profile as a random function [see Nikora et al., 1997] instead of identifying individual bedforms in a profile. A measure of the variability in bed elevations is the standard deviation of bed elevations, sometimes referred to as the interface width [Barabási and Stanley, 1995; Jerolmack and Mohrig, $2005 b]$. For a dune-covered bed, interface width grows as a power law with increasing domain length or window size. This power law growth holds for small window sizes. The power exponent characterizes the scaling of elevation fluctuations [Barabási and Stanley, 1995; Dodds and Rothman, 2000]. There is a gradual rollover of the interface width as the window size increases. We may characterize the location of rollover, i.e., the window size at which the rollover occurs, as
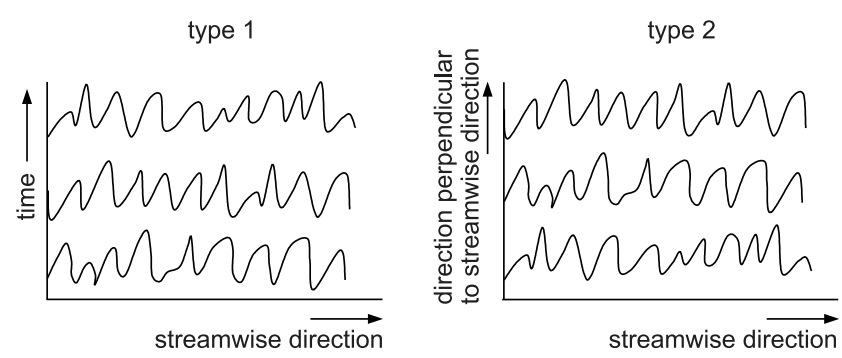

Figure 3. Two types of sets of bed elevation profiles are available: (1) time-dependent bed elevation profiles and (2) space-dependent bed elevation profiles. 


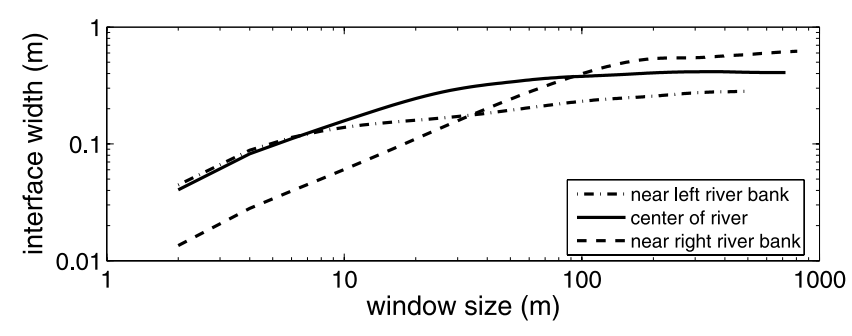

Figure 4. Interface width against window size for bed elevation profiles at 3 transects along the Waal branch of the Rhine River.

a characteristic bedform length [Jerolmack and Mohrig, $2005 \mathrm{~b}]$. The interface width associated with the location of rollover provides a characteristic bedform height. We consider a set of BEPs within a data set as statistically homogeneous if the characteristic bedform length, characteristic bedform height and the power exponent of the BEPs are equal.

[14] Within each flume and field data set, we group together BEPs of type 1 as, according to the spatial scaling technique, these BEPs are statistically homogeneous.

[15] In the flume experiments of Driegen [1986], Klaassen [1990], and Blom et al. [2003], BEPs were measured in the center of the flume, as well as left and right from the center. The spatial scaling technique shows that BEPs measured in the center deviate statistically from BEPs measured left and right from the center, which can be explained by sidewall influences. Therefore, for these experiments, we did not group together BEPs measured in the center with BEPs measured left and right from the center. Table 1 illustrates how for each experiment we have $m \times n$ sub data sets of statistically homogeneous flume BEPs. As a result, we obtain 168 flume sub data sets.

[16] Within the Waal branch reach measured in December 2006 the flow conditions and thus bedform geometry varies in space. For instance, near the banks the flow velocity and bedform geometry deviate from those in the center. Figure 4 shows interface width against window size for 3 transects along the Waal branch of the Rhine River. The location of gradual rollover of the 3 BEPs is different, indicating that these BEPs are not statistically homogeneous. The spatial scaling technique enables us to divide the reach into smaller reaches in which the BEPs are statistically homogeneous. This procedure results in 15 homogeneous sub data sets for the Waal data of December 2006, one homogeneous sub data set for the Waal data of March 2007, and two homogeneous sub data sets for the North Loup River data.

\subsection{Bedform Geometry From Bed Elevation Profiles}

[17] There exist several methods to find crest and trough locations and determine the geometric characteristics of individual bedforms. Examples of methods are (1) the manual selection of crests and troughs, (2) the selection of local maxima and minima and next the use of threshold values for bedform height and/or bedform length for selecting which of the maxima and minima are considered as crests and troughs, respectively, and (3) the selection of crests and troughs between zero upcrossings and zero downcrossings. Other matters that require consideration in the analysis of bedform geometry are how to detrend the BEPs (e.g., by fitting a linear line or by applying a moving average), and how to define the geometric variables. For instance, some authors define bedform length as the distance between two successive bedform troughs [e.g., Wang and Shen, 1980], others use the distance between two successive zero upcrossings [e.g., Annambhotla et al., 1972], or the distance between two crests [Crickmore, 1970].

[18] The method to find crest and trough locations and the above considerations may influence the resulting bedform geometry [Prent, 1998]. Choices are usually made subjectively on the basis of the whole bed configuration [Crickmore, 1970]. In order to compare various sets of measurements, we need to use the same method to find crests and troughs and to use the same definitions of geometric variables for each data set. Therefore it is generally not desirable to compare bedform data of different researchers if the original BEPs are lacking [Crickmore, 1970].

[19] Van der Mark and Blom [2007] have developed a bedform tracking tool which determines the geometry of the individual bedforms from original BEPs. The code has been applied to marine sand wave data [Van der Mark et al., 2008], flume data, and river data. Appendix A shortly describes the details of the bedform tracking tool. Figure 5 illustrates the definitions of geometric variables in the detrended BEP. In developing the bedform tracking tool, subjective decisions have been avoided as much as possible. The numerical code can easily be applied to various data sets, without the necessity to 'tune' the code to a data set or to define threshold values.

[20] We now have 186 sub data sets containing bedform geometry taken from the BEPs. The number of bedform heights, bedform lengths, crest elevations, and trough ele-

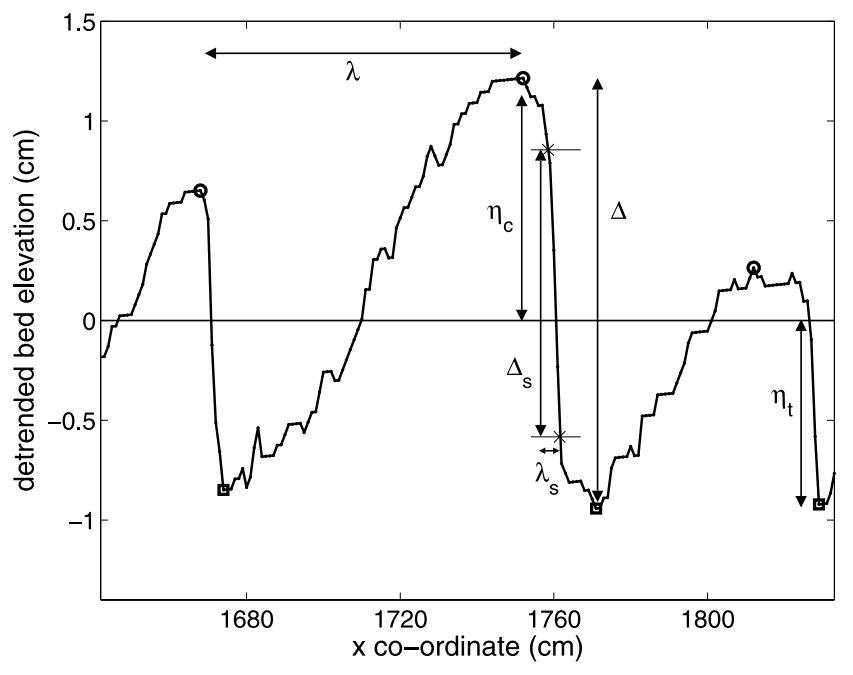

Figure 5. Definitions of the geometric variables in a detrended BEP: $\lambda$ denotes bedform length, $\Delta$ denotes bedform height, and $\eta_{c}$ and $\eta_{t}$ denote crest elevation and trough elevation, respectively. The lee face slope $S$ is defined as $\Delta_{s} / \lambda_{s}$. Crests and troughs are indicated with circles and squares, respectively. Flow is from left to right. 

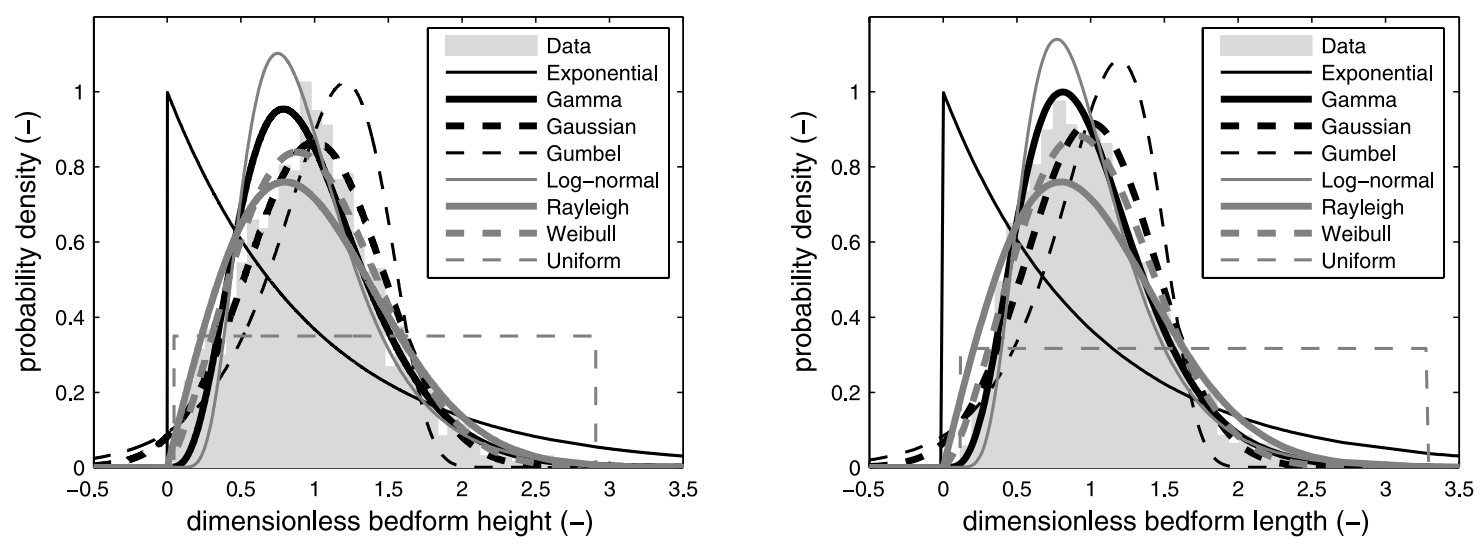

Figure 6. (a) Measured and imposed probability density functions of dimensionless bedform height (i.e., bedform height divided by mean bedform height) for a single sub data set, i.e., measurements in the center of the flume for experiment T37 [Driegen, 1986]. The number of bedform heights $N$ equals 1826 . (b) Measured and imposed probability density functions of dimensionless bedform length (i.e., bedform length divided by mean bedform length) for the same sub data set. The number of bedform lengths $N$ equals 1793.

vations in one sub data set equals at least 50 , and on average, about 900 .

\section{Probability Density Functions}

\subsection{Results}

[21] We analyze whether the five geometric variables are distributed according to a known probability density function. For each sub data set we determine the Exponential, Gamma, Gaussian, Gumbel, Log-normal, Rayleigh, Weibull, and Uniform distributions for each geometric variable. The distributions are determined using the mean and standard deviation of the geometric variable for each sub data set.

[22] Figure 6 shows an example of imposed probability density functions (PDFs) for dimensionless bedform heights and lengths measured in one of the flume experiments. Dimensionless bedform height is defined as the bedform height divided by the mean bedform height of the sub data set. For each sub data set we determine the goodness of the PDFs using an expression for the relative error $E_{X^{*}}$, which is equal to the integral of the absolute value of the difference between the measured and imposed PDF:

$$
E_{X^{*}}=\int_{0}^{\infty}\left|\left[p_{m}\left(X^{*}\right)-p_{i}\left(X^{*}\right)\right]\right| d X^{*}
$$

where $X^{*}$ denotes the dimensionless geometric variable, $p_{m}\left(X^{*}\right)$ denotes the measured PDF, and $p_{i}\left(X^{*}\right)$ denotes the imposed PDF. By definition, the integrals of the imposed PDF and measured PDF are equal to 1. If the measured PDF and imposed PDF are equal, the error is 0 , whereas if the measured PDF and imposed PDF do not overlap at all, the error is 2. For each of the imposed PDFs we determine the average error $\overline{E_{X *}}$ by averaging over all sub data sets. The imposed PDF with the smallest average error corresponds to the best approximation of the data. Table 2 presents the average error values for each imposed PDF for each geometric variable. In finding the best approximation, we have not fitted the PDFs to the data. We have imposed the mean value and the standard deviation of the specific geometric variable from the specific sub data set to the distribution.

[23] We find that for bedform height the Gaussian, Gamma, and Weibull distributions provide the best approximations. The Gamma, Log-normal, and Weibull distributions provide the best approximations for bedform length. For crest elevation, trough elevation, and lee face slope we find that the Weibull distribution yields the best approximation. It appears that for all five geometric variables, the Weibull distribution performs well. Depending on its shape parameter, $k$, the Weibull distribution can be positively skewed $(k<2.6)$, negatively skewed $(k>3.7)$, or not/hardly skewed $(2.6<k<3.7)$. All sub data sets appear to have shape parameters in the range $1.8-2.7$, which means that the imposed Weibull distributions are positively skewed.

[24] Many phenomena can be approximated well by the Gaussian distribution [e.g., Jenkins and Watts, 1968]. It appears that, except for the Gaussian distribution, the distributions yielding the best approximations are positively skewed. The reason we find positively skewed distributions to be good approximations of the data, may be that, by

Table 2. Average Error Values $\overline{E_{X} *}$ for the Goodness of the Imposed PDF for the Following Dimensionless Geometric Variables $\left(X^{*}\right)$ : Bedform Height $\Delta^{*}$, Bedform Length $\lambda^{*}$, Crest Elevation $\eta_{c}^{*}$, Trough Elevation $\eta_{t}^{*}$, and Lee Face Slope $S^{*}$

\begin{tabular}{lcccccccc}
\hline & Gaussian & Gamma & Rayleigh & Weibull & Exponential & Log-normal & Gumbel & Uniform \\
\hline$\Delta^{*}$ & 0.28 & $\mathbf{0 . 2 8}$ & 0.39 & $\mathbf{0 . 2 9}$ & 0.87 & 0.32 & 0.42 & 0.74 \\
$\lambda^{*}$ & 0.41 & $\mathbf{0 . 3 2}$ & 0.41 & $\mathbf{0 . 3 4}$ & 0.82 & $\mathbf{0 . 3 2}$ & 0.61 \\
$\eta_{c}{ }^{*}$ & 0.33 & 0.36 & 0.32 & $\mathbf{0 . 2 8}$ & 0.59 & 0.48 & 0.47 \\
$\eta_{t}^{*}$ & 0.35 & 0.32 & 0.37 & $\mathbf{0 . 2 8}$ & 0.55 & 0.44 & 0.51 \\
$S^{*}$ & 0.47 & 0.53 & 0.52 & 0.43 & 0.73 & 0.63 & 0.50 & 0.70 \\
\hline
\end{tabular}



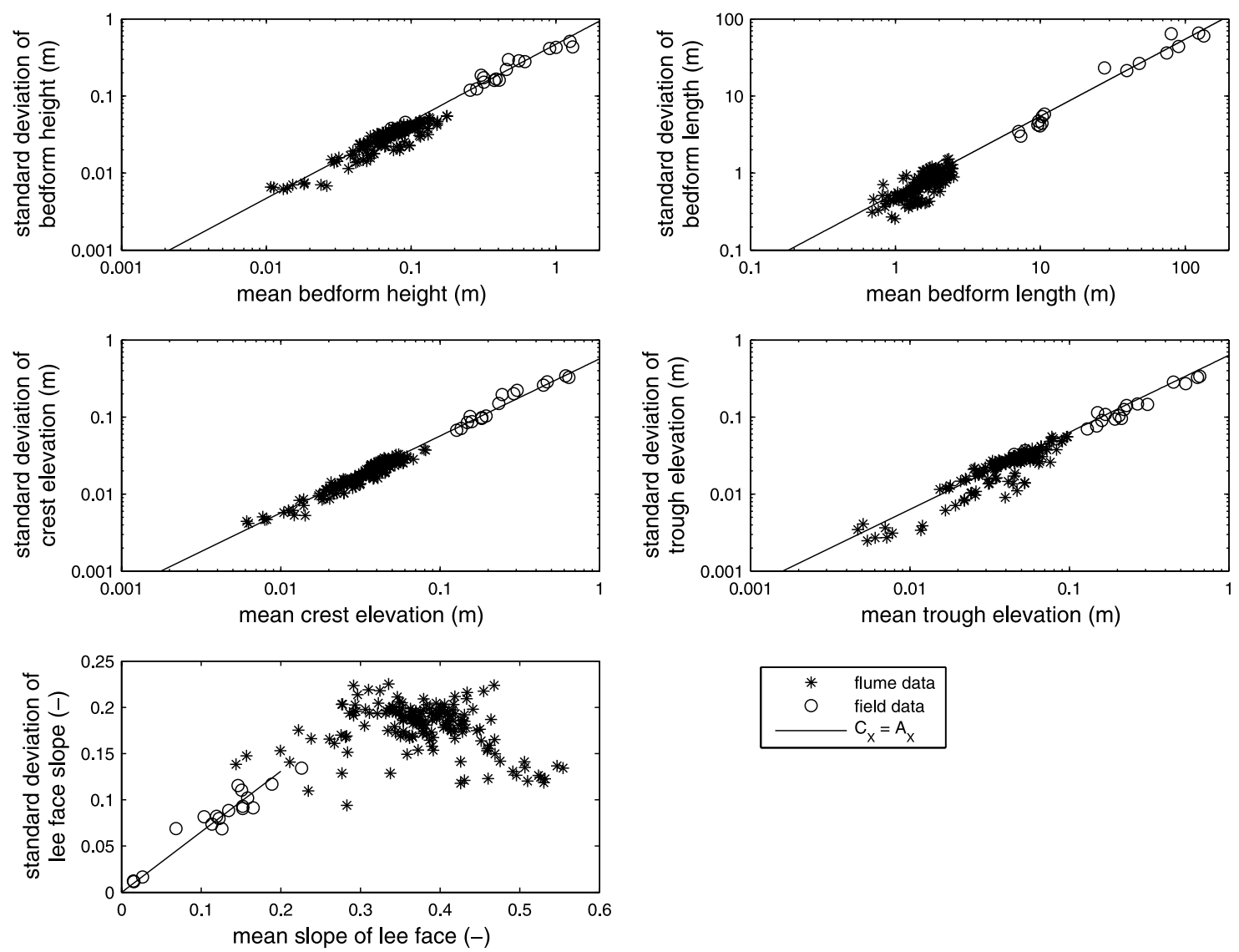

Figure 7. Standard deviation against mean value for (a) bedform height, (b) bedform length, (c) crest elevation, (d) trough elevation, and (e) lee face slope. The solid lines represent equation (4).

definition, in our analysis the five geometric variables are positive values (Figure 5). We recommend the Weibull, Gamma, or Log-normal distributions rather than the Gaussian, Gumbel, or Uniform distributions, as the latter distributions admit negative values.

\subsection{Discussion}

[25] Previous researchers have assigned several types of probability density functions to bedform heights and bedform lengths as found from BEPs of flume and field experiments. For instance, bedform height is identified as following the Rayleigh distribution [Ashida and Tanaka, 1967; Nordin, 1971], the Weibull distribution [Wang and Shen, 1980], the Exponential distribution [Annambhotla et al., 1972], the Gamma distribution [Leclair et al., 1997], the Gaussian distribution [Mahmood and Ahmadi-Karvigh, 1976], and the Beta distribution [Prent and Hickin, 2001]. We mention four reasons why different types of optimal PDFs have been found: (1) differences in the preprocessing of the measured bed elevation profiles (e.g., different methods to remove outliers, to detrend the BEPs, or to filter the BEPs), (2) differences in the methods to determine the locations of crests and troughs, (3) differences in the definition of geometric variables, and (4) differences with respect to the types of imposed PDFs used in the analysis. For instance, Mahmood and Ahmadi-Karvigh [1976] compare their bedform length data to Gaussian, Exponential,
Cauchy, Uniform, and Rayleigh distributions and not to, for example, the Weibull distribution.

\section{Coefficient of Variation}

\subsection{Results}

[26] In the present study we focus on finding generic relations describing variability in the five geometric stochastic variables. We study the variability in each geometric variable $X$ by determining for each sub data set the mean value $\mu_{X}$, the standard deviation $\sigma_{X}$, and the coefficient of variation $C_{X}$, which is defined as the ratio of the standard deviation to the mean value:

$$
C_{X}=\frac{\sigma_{X}}{\mu_{X}}
$$

in which $X$ denotes the geometric stochastic variable (i.e., bedform height, bedform length, crest elevation, trough elevation, or lee face slope).

[27] For bedform height, Figure $7 \mathrm{a}$ shows the standard deviation as a function of the mean value. Figure $7 \mathrm{a}$ also shows that a more or less linear relation exists between the standard deviation of bedform height and the mean bedform height. Figures $7 \mathrm{~b}, 7 \mathrm{c}$, and $7 \mathrm{~d}$ show that such linear relations also exist for bedform length, crest elevation, and trough elevation, respectively. 

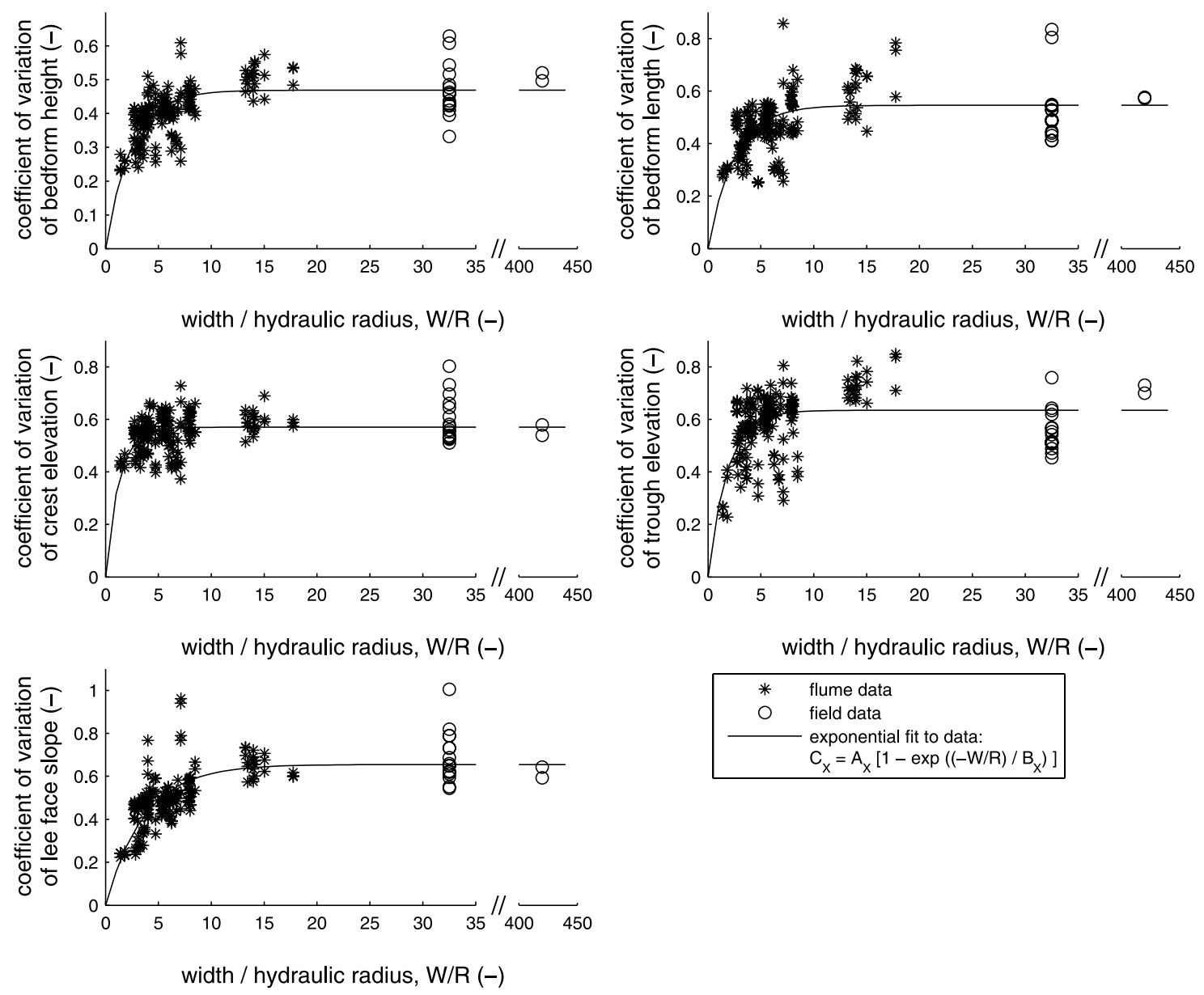

width / hydraulic radius, W/R (-)

\begin{tabular}{|ll|}
\hline$*$ & flume data \\
$\bigcirc$ & field data \\
& exponential fit to data: \\
& $C_{\mathrm{X}}=A_{\mathrm{x}}\left[1-\exp \left((-\mathrm{W} / \mathrm{R}) / \mathrm{B}_{\mathrm{X}}\right)\right]$ \\
\hline
\end{tabular}

Figure 8. Coefficient of variation against the flume or river width divided by hydraulic radius for (a) bedform height, (b) bedform length, (c) crest elevation, (d) trough elevation, and (e) lee face slope. The solid lines represent equation (3).

[28] Figure 7e shows the standard deviation against the mean value for the lee face slope. The scatter is large and no linear relation exists between the standard deviation and the mean value for the lee face slope, especially for mean lee face slopes larger than 0.2. Roughly, we may see a linear trend in the field data. The standard deviation of the flume data roughly varies between 0.13 and 0.22 , which appears to be independent of the mean lee face slope. The fact that lee face slopes cannot become much steeper than the natural angle of repose of the sediment may explain why the linear trend disappears for increasing lee face slope. It appears that lee faces in the flume are significantly steeper than those in the field, which is also found by Best and Kostaschuk [2002].

[29] We have seen that a more or less linear relation exists between standard deviation and mean geometric variable, which means that the coefficient of variation is a more or less constant value. We now analyze the effects of the ratio of flume or river width to hydraulic radius on the coefficient of variation in Figure 8. The hydraulic radius of the flume experiments is corrected for sidewall roughness using the method of Vanoni and Brooks [1957]. For the five geometric variables, Figure 8 shows that their coefficients of variation decrease with decreasing ratio of flume width to hydraulic radius for ratios smaller than about ten. For each geometric variable we fit the following exponential function through the data points:

$$
C_{X}=A_{X}\left[1-\exp \left(\frac{-W / R}{B_{X}}\right)\right]
$$

in which $C_{X}$ denotes the coefficient of variation of geometric variable $X, W$ denotes the flume or river width, $R$ denotes the hydraulic radius, and $A_{X}$ and $B_{X}$ denote constants. Table 3 presents the constants $A_{X}$ and $B_{X}$ for each geometric variable $X$. The exponential function simply expresses that for relatively narrow flume widths the variability in bedform geometry is restricted. For ratios of

Table 3. Constants $A_{X}$ and $B_{X}$ (equation 3) and Coefficients Relating the $95 \%$ and $98 \%$ Values of Geometric Bedform Variables to Their Standard Deviations

\begin{tabular}{lcccc}
\hline$X$ & $A_{X}$ & $B_{X}$ & $C_{X 95}$ & $C_{X 98}$ \\
\hline$\Delta$ & 0.47 & 2.4 & 1.7 & 2.2 \\
$\lambda$ & 0.55 & 2.5 & 1.9 & 2.6 \\
$\eta_{c}$ & 0.57 & 1.2 & 1.7 & 2.0 \\
$\eta_{t}$ & 0.63 & 1.8 & 1.8 & 2.3 \\
$S$ & 0.66 & 3.7 & - & - \\
\hline
\end{tabular}




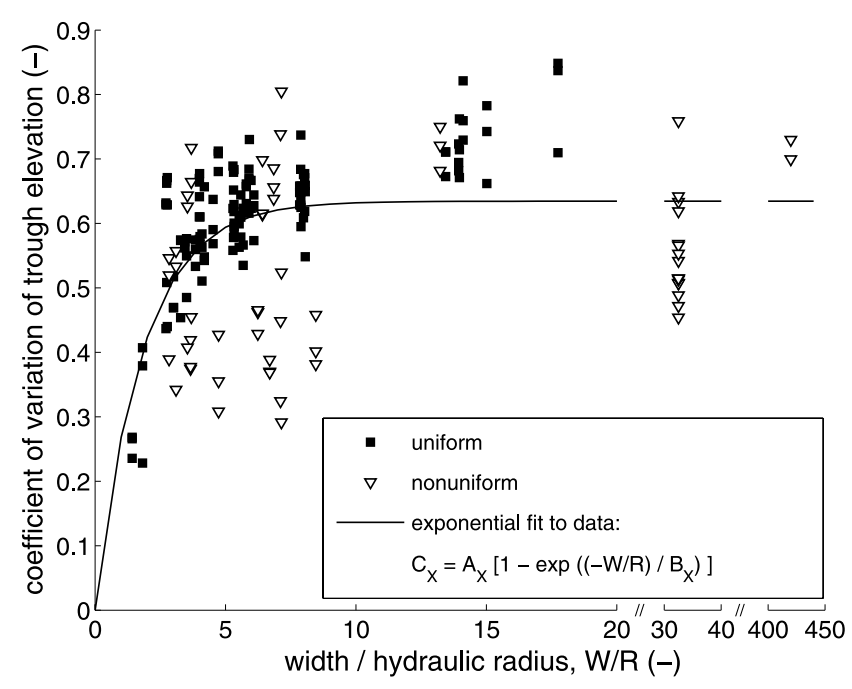

Figure 9. Coefficient of variation of trough elevation against the flume or river width divided by hydraulic radius. Distinction is made between uniform and nonuniform sediment experiments.

width to hydraulic radius larger than about ten, the coefficient of variation of stochastic variable $X$ becomes:

$$
C_{X}=A_{X}
$$

[30] In Figure 7, the solid lines represent equation (4). We can see that for field conditions, where ratios of width to water depth are usually larger than ten, equation (4) can be used to get an estimate of the variability in bedform geometry. Figure 8 shows that variability in bedform geometry in flume experiments is comparable to variability in field measurements if the ratio of width to hydraulic radius is larger than ten.

[31] Williams [1970] has shown that the flume width influences the mean geometric bedform variables. Also, Crickmore [1970] reports an increase of both mean bedform length and bedform height for increasing values of the ratio of width to water depth for the same specific discharge. We have shown that bedform variability decreases with decreasing ratio of width to water depth. These results are confirmed with respect to bedform length by the findings of Van Rijn and Klaassen [1981]. For a relatively narrow flume, the flow separation behind a dune will be more or less uniform over the width of the flume and the recirculation will be stable. A relatively wider flume may result in a recirculation pattern that is unstable in lateral direction, which may restrict the width of a bedform. As a result, more than one bedform may occur over the width of a flume, which may result in more variability.

[32] Figure 8 shows that some sub data sets have more regular bedform geometry (i.e., a relatively small coefficient of variation) than other sub data sets having similar ratios of width to hydraulic radius. Sediment sorting processes may explain differences in bedform variability between sub data sets. For instance, the presence of a coarse layer underneath migrating bedforms reduces the variability in trough elevations [Wilcock and Southhard, 1989; Blom et al., 2003;
Leclair and Blom, 2005]. Figure 9 shows the coefficient of variation of trough elevation against the flume or river width divided by hydraulic radius, and we distinguish between sub data sets with uniform sediment and sub data sets with nonuniform sediment. A nonuniform sediment mixture is here defined as a mixture with a geometric standard deviation $\left(\sigma_{g}=\sqrt{D_{84} / D_{16}}\right)$ larger than 1.6 [Diplas and Sutherland, 1988]. From Figure 9, it appears that roughly the coefficient of variation for uniform sediment experiments is larger than for nonuniform sediment experiments in which a coarse layer underneath the bedforms may develop.

[33] However, it may be better to have a criterion based on partial transport rather than the above criterion in order to distinguish between experiments with and without the formation of a coarse layer. Partial transport is here defined as the condition in which the coarsest grain sizes in the mixture are not (significantly) entrained or transported by the flow [Blom et al., 2003]. For many of the flume and field experiments studied here data on partial transport is unavailable. We therefore recommend further research on this topic.

\subsection{Discussion}

[34] We have seen that, for sufficiently large ratios of width to hydraulic radius, the standard deviation of bedform height increases linearly with the mean bedform height. Often a relationship exists between the standard deviation and the mean of a sample, such that the larger the mean, the larger the standard deviation [Sincich, 1985]. For instance, daily maximum wind speed analyzed at several locations in several months satisfies this condition [Yan et al., 2002].

[35] For the Calamus River, Nebraska, USA, Gabel [1993] finds values for the coefficient of variation of bedform height $C_{\Delta}$ varying between 0.34 and 0.53 , with a mean coefficient of variation of 0.44 , which is close to the proposed value $\left(C_{\Delta}=A_{\Delta}=0.47\right)$. Also, the flume data by Wang and Shen [1980] $\left(W / h \approx 8, C_{\Delta}\right.$ ranges between 0.41 and 0.50$)$ and Leclair et al. [1997] $\left(W / h \approx 5, \mathrm{C}_{\Delta}\right.$ ranges between 0.39 and 0.48 ) agree to the proposed coefficient of variation of bedform height.

[36] The proposed value of the coefficient of variation of bedform length, $\mathrm{C}_{\lambda}=\mathrm{A}_{\lambda}=0.55$, appears to be somewhat larger than the one found by Gabel [1993] for the Calamus River. Smaller coefficients of variation of bedform length are also found by Wang and Shen [1980] and Leclair et al. [1997], also when taken into account the reduction in variability due to the flume width effect. This is probably due to the fact that they remove small scale bedforms from their analysis, which results in a larger mean bedform length and a smaller standard deviation of bedform length.

[37] Some of the considered reaches of the Waal branch consist of (secondary) bedforms superimposed on larger (primary) bedforms. We have analyzed the coefficients of variation of geometric variables for the primary and the secondary bedforms separately. There appear to be no significant differences between the coefficients of variation for primary and secondary bedform geometry.

[38] Figure 8 shows that, although the coefficients of variation of bedform geometry are more or less constant for ratios of width to hydraulic radius larger than about ten, there is quite some scatter. Some sub data sets have 

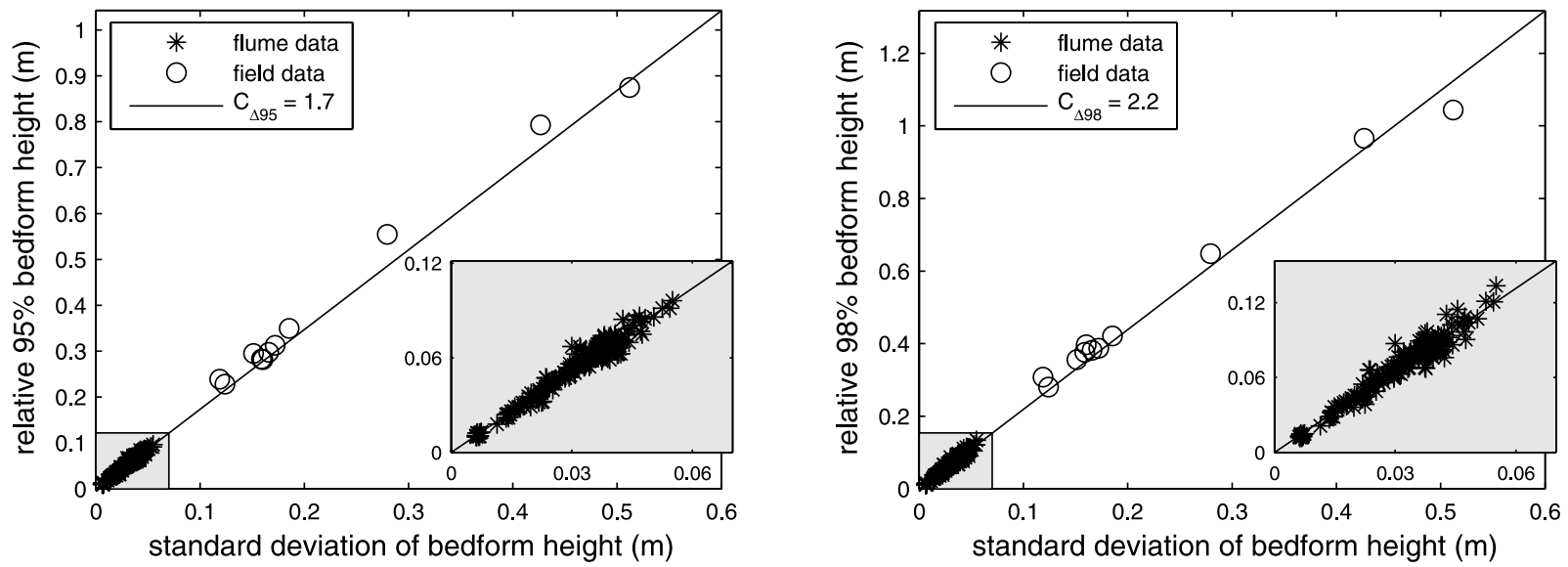

Figure 10. (a) Relative $95 \%$ bedform height, $\Delta_{95}-\mu_{\Delta}$, against standard deviation of bedform height, $\sigma_{\Delta}$. (b) Relative $98 \%$ bedform height, $\Delta_{98}-\mu_{\Delta}$, against standard deviation of bedform height, $\sigma_{\Delta}$.

somewhat more regular bedform geometry than other sub data sets. It appears that if bedform heights are relatively regular, bedform lengths, crest elevations, and trough elevations are relatively regular, as well.

\section{Extreme Values}

\subsection{Results}

[39] We analyze the $95 \%$ and $98 \%$ values for bedform height, bedform length, crest elevation, and trough elevation, in order to get insight in the extreme values of the distribution. We only consider the sub data sets in which the sample size is larger than 100 in order to have a sufficiently accurate estimate of the $95 \%$ and $98 \%$ values.

[40] Figure 10a shows the relative $95 \%$ bedform height, i.e., the $95 \%$ bedform height minus the mean bedform height $\left(\Delta_{95}-\mu_{\Delta}\right)$, as a function of the standard deviation of bedform height. For bedform height we find that

$$
C_{\Delta 95}=\frac{\Delta_{95}-\mu_{\Delta}}{\sigma_{\Delta}}=1.7
$$

where the coefficient $C_{\Delta 95}$ is a constant relating the $95 \%$ bedform height to the standard deviation of bedform height. This means that we can predict the $95 \%$ bedform height from the mean bedform height and the measured or predicted standard deviation:

$$
\Delta_{95}=C_{\Delta 95} \sigma_{\Delta}+\mu_{\Delta}
$$

[41] With equation (2), this becomes

$$
\Delta_{95}=\mu_{\Delta}\left(C_{\Delta 95} C_{\Delta}+1\right)
$$

in generic form

$$
X_{95}=\mu_{X}\left(C_{X 95} C_{X}+1\right)
$$

[42] This means that we can determine the $95 \%$ value if the mean value is predicted using some submodel for mean bedform height and using the proposed coefficients in Table 3. Similar to equation (5), for bedform length $C_{\lambda 95}$ equals 1.9, for crest elevation $C_{\eta c 95}$ equals 1.7 , and for trough elevation $C_{\eta c 95}$ equals 1.8 (Table 3 ).

[43] Figure 10b shows the relative $98 \%$ bedform height, i.e., the $98 \%$ bedform height minus the mean bedform height $\left(\Delta_{98}-\mu_{\Delta}\right)$, as a function of the standard deviation of bedform height. Table 3 shows the coefficients $C_{\Delta 98}$, $C_{\lambda 98}, C_{\eta c 98}, C_{\eta t 98}$, relating the $98 \%$ values for bedform height, bedform length, crest elevation, and trough elevation to their respective standard deviations. Given these coefficients, we are able to predict the $98 \%$ value of the geometric variable, $X$, from the mean value, $\mu_{X}$, and the measured or predicted standard deviation of the geometric variable, $\sigma_{X}$ :

$$
X_{98}=C_{X 98} \sigma_{X}+\mu_{X}
$$

[44] Or, with equation (2), this becomes

$$
X_{98}=\mu_{X}\left(C_{X 98} C_{X}+1\right)
$$

\subsection{Discussion}

[45] Theoretically it can be shown that $C_{X 95}$ equals 1.64 and $C_{X 98}$ equals 2.05 if the stochastic variable $X$ follows a Gaussian distribution, independent of the values of $\mu_{X}$ and $\sigma_{X}$. A value of $C_{X 95}$ or $C_{X 98}$ that is larger than the value of 1.64 or 2.05 indicates that the extreme value is more remote from the mean value than in the case of a Gaussian distribution. This confirms the finding in section 4 that geometric bedform variables are distributed according to a type of distribution that has a longer tail for the higher values.

\section{Conclusions}

[46] We have studied the stochastics of bedform geometry for both flume and field data. The five geometric variables bedform height, bedform length, crest elevation, trough elevation and lee face slope are best described using a positively skewed probability density function. The Weibull distribution performs well for the considered geometric variables. 
[47] The stochastics of bedform geometry can be characterized using simple generic relationships. Linear relations exist between standard deviation and mean value for bedform height, bedform length, crest elevation, and trough elevation if the ratio of width to hydraulic radius is larger than about ten. As such, a constant coefficient of variation can be applied to quantify variability in bedform geometry. For field conditions, a constant coefficient of variation is a good approximation. If the ratio of width to hydraulic radius is smaller than about ten, variability in bedform height, bedform length, crest elevation, and trough elevation is restricted, which may be represented by an exponential function for the coefficient of variation.

[48] For field data, the mean lee face slope is significantly smaller than for flume data, and the standard deviation scales with the mean lee face slope. For flume data the standard deviation does not scale with the mean lee face slope, as the slope cannot become much steeper than the natural angle of repose.

[49] The $95 \%$ and $98 \%$ values of the geometric variables scale with their standard deviation, so that we are able to predict the extremes using the proposed relations and given the mean values for the geometric variables.

[50] The proposed relations between mean geometric variables and their standard deviations, and 95\% and 98\% values are useful for, for instance, engineering studies. The relations can be applied to determine an estimate of the extremes in crest elevation in a navigational channel, or to determine the optimal depth of a tunnel or trench to place a pipeline in.

\section{Appendix A: Bedform Tracking Tool}

[51] Van der Mark and Blom [2007] have developed a bedform tracking tool which determines the geometric variables of individual bedforms from the original bed elevation profiles (BEPs). In short, the procedure of the bedform tracking tool is as follows:

[52] 1. For each BEP we find and replace outliers.

[53] 2. For each BEP we determine the trend line. We choose either a linear trend line or a weighted moving average trend line. As all flume experiments were conducted under steady and uniform conditions (i.e., no spatial variations), the trend line is best described by a linear fit to the measured bed elevations. For the field measurements, the trend line is rather represented by a moving average.

[54] 3. We detrend the BEP using the trend line so that the detrended BEP fluctuates around the zero line.

[55] 4. We apply a weighted moving average filter which yields a filtered BEP. The filtered BEP is only used to avoid the effect of small fluctuations in the BEP around the zero line on the resulting zero up- and downcrossings.

[56] 5. We determine zero upcrossings and zero downcrossings in the filtered BEP.

[57] 6. We determine crests and troughs in the original BEP. A crest is located at the maximum value between a zero up- and zero downcrossing. A trough is located at the minimum value between a zero down- and zero upcrossing.

[58] 7. We determine the geometry of individual bedforms in the detrended BEP (bedform height, $\Delta$, bedform length, $\lambda$, crest elevation, $\eta_{c}$, trough elevation, $\eta_{t}$, and lee face slope, $S$, see Figure 5). We define crest elevation as the vertical distance from crest to zero line, and trough eleva- tion as the vertical distance from trough to zero line. Bedform height is defined as the vertical distance between crest and downstream trough. Bedform length is defined as the horizontal distance between two consecutive crests. The lee face slope is defined as the vertical distance divided by the horizontal distance of a distinct part of the lee face. To determine the lee face slope we exclude a distance of one sixth of the bedform height below the crest and a distance of one sixth of the bedform height above the trough as these regions are usually transitional areas.

\section{Notation}

$A_{X}$ constant, dimensionless.

$B_{X}$ constant, dimensionless.

$C_{X}$ coefficient of variation of stochastic variable $X$, dimensionless.

$C_{X 95}$ coefficient relating the $95 \%$ value of stochastic variable $X$ minus the mean of $X$ to the standard deviation of $X$, dimensionless.

$C_{X 98}$ coefficient relating the $98 \%$ value of stochastic variable $X$ minus the mean of $X$ to the standard deviation of $X$, dimensionless.

$D_{x}$ particle diameter for which $x \%$ of the material is finer, $\mathrm{mm}$.

$E_{X^{*}}$ error value for the goodness of an imposed PDF relative to the measured PDF of dimensionless stochastic variable $X^{*}$, dimensionless.

$\overline{E_{X^{*}}}$ error value for the goodness of an imposed PDF relative to the measured PDF of dimensionless stochastic variable $X^{*}$, averaged over all considered experiments, dimensionless.

$h$ water depth, m.

$k$ shape parameter of Weibull distribution, dimensionless.

$L$ flume length, m.

$m$ number of transect locations, dimensionless.

$n$ number of flume experiments, dimensionless.

$N$ sample size, dimensionless.

$p_{i}(X)$ imposed probability density function of stochastic variable $X$, unity as for $X^{-1}$.

$p_{m}(X)$ measured probability density function of stochastic variable $X$, unity as for $X^{-1}$.

$R$ hydraulic radius, $\mathrm{m}$.

$S$ slope of the lee face of a bedform $\left(S=\Delta_{S} / \lambda_{S}\right)$, dimensionless.

$U$ average flow velocity, $\mathrm{m} / \mathrm{s}$.

$W$ flume or river width, $\mathrm{m}$.

$X$ stochastic variable, unity as for the variable. In this study: bedform height, bedform length, crest elevation, trough elevation, lee face slope.

$X^{*}$ dimensionless stochastic variable.

$X_{95} \quad 95 \%$ value of stochastic variable $X$, unity as for $X$.

$X_{98} \quad 98 \%$ value of stochastic variable $X$, unity as for $X$.

$\Delta$ bedform height, $\mathrm{m}$.

$\Delta_{S}$ part of bedform height that is used to determine lee face slope, $\mathrm{m}$.

$\eta_{c} \quad$ crest elevation, $\mathrm{m}$.

$\eta_{t}$ trough elevation, $\mathrm{m}$.

$\lambda$ bedform length, $\mathrm{m}$.

$\lambda_{S}$ part of bedform length that is used to determine lee face slope, $\mathrm{m}$. 
$\mu_{X}$ mean value of stochastic variable $X$, unity as for $X$.

$\sigma_{g}$ geometric standard deviation of sediment mixture, dimensionless.

$\sigma_{X}$ standard deviation of stochastic variable $X$, unity as for $X$.

[59] Acknowledgments. The authors would like to acknowledge the Institute for Inland Water Management and Waste Water Treatment (J. Sieben and A. J. A. Wagener) for providing the Waal branch data, S. F. Leclair for providing flume data, D. Mohrig and D. J. Jerolmack for providing the North Loup data, and S. F. Leclair and S. R. McLean for their useful review comments. An earlier and less extended version of this work was published in "River, Coastal and Estuarine Morphodynamics: RCEM 2007: Proceedings of the Fifth IAHR Symposium on River, Coastal and Estuarine Morphodynamics", held in Enschede, Netherlands, 17-21 September 2007, edited by C. M. Dohmen-Janssen and S. J. M. H. Hulscher, and published by Taylor \& Francis, Leiden/ London, 2007. The results in the present paper supersede those in the prior RCEM paper. This research project, which is part of the VICI project ROUGH WATER (project number TCB6231), is supported by the Technology Foundation STW, applied science division of Netherlands Organization for Scientific Research (NWO) and the technology program of the Ministry of Economic Affairs.

\section{References}

Allen, J. R. L. (1983), River bedforms: Progress and problems, in Modern and Ancient Fluvial Systems, vol. 6, edited by J. D. Collinson and J. Lewin, pp. 19-33, Int. Assoc. Sedimentol. Spec. Publ., Blackwell, Boston.

Amsler, M. L., and M. H. García (1997), Discussion: Sand dune geometry of large rivers during floods, J. Hydraul. Eng., 123, 582-585.

Annambhotla, V. S. S., W. W. Sayre, and R. H. Livesey (1972), Statistical properties of Missouri River bedforms, J. Waterw., Harbors Coastal Eng. Div., 98(WW4), 489-510.

Ashida, K., and Y. Tanaka (1967), A statistical study of sand waves, in Proc. 12th IAHR Congress, pp. 103-110, Fort Collins, Colorado.

Barabási, A.-L., and H. E. Stanley (1995), Fractal Concepts in Surface Growth, Cambridge University Press, New York.

Best, J., and R. Kostaschuk (2002), An experimental study of turbulent flow over a low-angle dune, J. Geophys. Res., 107(C9), 1118-1129, 3135, doi:10.1029/2000JC000294.

Blom, A., J. S. Ribberink, and H. J. De Vriend (2003), Vertical sorting in bed forms: Flume experiments with a natural and a trimodal sediment mixture, Water Resour. Res., 39(2), 1025, doi:10.1029/2001WR001088.

Blom, A., J. S. Ribberink, and G. Parker (2008), Vertical sorting and the morphodynamics of bed form-dominated rivers: A sorting evolution model, J. Geophys. Res., 113, F01019, doi:10.1029/2006JF000618.

Crickmore, M. J. (1970), Effect of flume width on bedform characteristics, J. Hydraul. Eng. Div., 96(HY2), 473-496.

Diplas, P., and A. J. Sutherland (1988), Sampling techniques for gravel sized sediments, J. Hydraul. Eng., 114(5), 484-501.

Dodds, P. S., and D. H. Rothman (2000), Scaling, universality and geomorphology, Annu. Rev. Earth Planet. Sci., 28, 571-610.

Driegen, J. (1986), Flume experiments on dunes under steady flow conditions (uniform sand, $\mathrm{Dm}=0.77 \mathrm{~mm}$ ). Description of bed forms, $T O W$ Report R 657 - XXVII / M 1314 part XV, WL|Delft Hydraulics, Delft, Netherlands.

Gabel, S. L. (1993), Geometry and kinematics of dunes during steady and unsteady flows in the Calamus River, Nebraska, USA, Sedimentology, 40, $237-269$.

Hulscher, S. J. M. H. (1996), Tidal induced large-scale regular bed form patterns in a three-dimensional shallow water model, J. Geophys. Res., 101(C9), 20,727-20,744.

Jenkins, G. M., and D. G. Watts (1968), Spectral Analysis and Its Applications, Holden Day, San Francisco, California.

Jerolmack, D. J., and D. Mohrig (2005a), Interactions between bed forms: Topography, turbulence, and transport, J. Geophys. Res., 110, F02014, doi: $10.1029 / 2004 J F 000126$.

Jerolmack, D. J., and D. Mohrig (2005b), A unified model for subaqueous bed form dynamics, Water Resour. Res., 41, W12421, doi:10.1029/ 2005WR004329.

Klaassen, G. J. (1990), Experiments with graded sediments in a straight flume. Vol. A (Text) and Vol. B (Tables and Figures), Tech. Rep. Q788, WL|Delft Hydraulics.

Leclair, S. F. (2002), Preservation of cross-strata due to the migration of subaqueous dunes: An experimental investigation, Sedimentology, 49, $1157-1180$.
Leclair, S. F., and A. Blom (2005), A qualitative analysis of the distribution of bed-surface elevation and the characteristics of associated deposits for subaqueous dunes, Spec. Publ. Int. Assoc. Sedimentol., 35, 121-134.

Leclair, S. F., J. S. Bridge, and F. Wang (1997), Preservation of cross-strata due to migration of subaqueous dunes over aggrading and non-aggrading beds: Comparison of experimental data with theory, Geosci. Can., 24(1), $55-66$.

Lyn, D. A. (1993), Turbulence measurements in open-channel flows over artificial bed forms, J. Hydraul. Eng., 119(3), 306-326.

Mahmood, K., and H. Ahmadi-Karvigh (1976), Analysis of bed profiles in sand bed canals, in Proc. Rivers '76, ASCE Waterways, Harbors and Coastal Engineering Division Specialty Conference.

McLean, S. R., S. R. Wolfe, and J. M. Nelson (1999), Spatially averaged flow over a wavy boundary revisited, J. Geophys. Res., 104(C7), $15,743-15,753$.

Mohrig, D. (1994), Spatial evolution of dunes in a sandy river, Ph.D. thesis, University of Washington, Seattle, USA.

Mohrig, D., and J. D. Smith (1996), Predicting the migration rates of subaqueous dunes, Water Resour. Res., 32(10), 3207-3217.

Nelson, J. M., S. R. McLean, and S. R. Wolfe (1993), Mean flow and turbulence fields over two-dimensional bed forms, Water Resour. Res., 29(12), 3935-3953.

Nikora, V. I., and D. M. Hicks (1997), Scaling relationships for sand wave development in unidirectional flow, J. Hydraul. Eng., 123(12), 1152-1156.

Nikora, V. I., A. N. Sukhodolov, and P. M. Rowinski (1997), Statistical sand wave dynamics in one-directional water flows, J. Fluid Mech., 351, $17-39$.

Nordin, C. F. (1971), Statistical properties of dune profiles. Sediment transport in alluvial channels, U.S. Geological Survey Professional Paper, 562-F. US Government Printing Office, Washington.

Paola, C., and L. Borgman (1991), Reconstructing random topography from preserved stratification, Sedimentology, 38, 553-565.

Prent, M. T. H. (1998), Seasonal regime of bedform and hydraulic geometry, Lillooet River, Pemberton, BC., Master's thesis, Simon Fraser University.

Prent, M. T. H., and E. J. Hickin (2001), Annual regime of bedforms, roughness and flow resistance, Lillooet River, British Columbia, BC, Geomorphology, 41, 369-390.

Sincich, T. (1985), Statistics by Example, 2nd ed., Dellen Pub Co, San Francisco.

Ten Brinke, W. B. M. (1997), Bed composition of the rivers Waal and IJssel in 1966, 1976, 1984 and 1995 (in Dutch), Tech. Rep. 97.009 ISBN 9036950562, Institute for Inland Water Management and Waste Water Treatment, Netherlands.

Van der Mark, C. F., and A. Blom (2007), A new and widely applicable tool for determining the geometric properties of bedforms, CE\&M Research Report 2007R-003/WEM-002 ISSN 1568-4652, University of Twente, Enschede, Netherlands.

Van der Mark, C. F., M. F. De Koning, A. Blom, S. J. M. H. Hulscher, and A. Stolk (2008), Sea bed sand waves studied to help pipeline planners, Pipeline Gas J., 235(4), 78-81.

Van Rijn, L. C. (1982), Equivalent roughness of alluvial bed, J. Hydraul. Eng. Div., 108(HY10), 1215-1218.

Van Rijn, L. C., and G. J. Klaassen (1981), Experience with straight flumes for movable bed experiments, in Proc. IAHR Workshop on Particle Motion and Sediment Transport, HY10, Rapperswil, Switzerland.

Vanoni, V. A., and N. H. Brooks (1957), Laboratory studies of the roughness and suspended load of alluvial streams, Tech. Rep. E-68, Sediment. Lab., Calif. Inst. of Technol., Pasadena, USA.

Wang, W. C., and H. W. Shen (1980), Statistical properties of alluvial bed forms, in Proc. 3rd Int. Symposium on Stochastic Hydraulics, pp. 371389, Tokyo, Japan.

Wilcock, P. R., and J. B. Southard (1989), Bed load transport of mixed size sediment: Fractional transport rates, bed forms, and the development of a coarse bed surface layer, Water Resour. Res., 25(7), 1629-1641.

Williams, G. P. (1970), Flume width and water depth effects in sediment transport experiments, U.S. Geological Survey Professional Paper, 562-H. US Government Printing Office, Washington.

Yan, Z., S. Bate, R. E. Chandler, V. Isham, and H. Wheater (2002), An analysis of daily maximum wind speed in northwestern Europe using generalized linear models, J. Clim., 15(15), 2073-2088.

Yoon, J. Y., and V. C. Patel (1996), Numerical model of turbulent flow over sand dune, J. Hydraul. Eng., 122(1), 10-18.

A. Blom, Environmental Fluid Mechanics, Delft University of Technology, P.O. Box 5048, 2600 GA Delft, Netherlands. (astrid.blom@tudelft.nl)

S. J. M. H. Hulscher and C. F. van der Mark, Water Engineering and Management, Civil Engineering, University of Twente, P.O. Box 217, 7500 AE Enschede, Netherlands. (s.j.m.h.hulscher@utwente.nl; c.f.vandermark@ utwente.nl) 